\title{
Reflection Profiles of the Active Seismic and Volcanic Region off the East Coast of Izu Peninsula
}

\author{
Keiji Kasahara, ${ }^{1, *}$ Fumio Yamamizu, ${ }^{1}$ Akihisa Takahashi, ${ }^{2}$ \\ and Takeshi Ikawa ${ }^{2}$ \\ ${ }^{1}$ National Research Institute for Earthscience and Disaster Prevention, \\ Tsukuba 305, Japan \\ ${ }^{2}$ JAPEX Geoscience Institute, Inc., Minato-ku, Tokyo 107, Japan
}

\begin{abstract}
VIBROSEIS reflection explorations profiled the crustal structure under the east coast of Izu Peninsula where a seabed volcano erupted on July 13, 1989. Profiles along two exploration lines show a common feature that consists of three layers. The uppermost layer is floored with relatively intense reflections from shallow depths within $0.5 \mathrm{~s}$ of two-way travel time, the next one is rather transparent layer, and the last is the basement ceiled with weaker reflections around $1.0 \mathrm{~s}$. The shallower reflectors are seen to be broken here and there. The depth of deeper reflector correctly coinsides with the upper limit of the earthquake swarm which is concentrated to the depth range of $2-4 \mathrm{~km}$. It is the most interesting that narrow spot-like high velocity bodies are found in the shallowest crust near the seismic swarm area. We suppose that those bodies may be interpreted as aged magma intrusions, and may create an asperity of the major earthquake of M5.5 prior to the submarine volcanic eruption.
\end{abstract}

\section{Introduction}

After the Izu-hanto-oki earthquake (M6.9) in 1974, the seismicity around the Izu Peninsula became more active. The latest Ito-oki swarm activities, which began in May 1989, accompanied a number of felt earthquakes, severe volcanic tremors, and finally developed into an unwitnessed seabed volcanic eruption on July 13, 1989. Several days prior to the eruption, the largest earthquake of $M 5.5$ occurred on the coast line near Ito. This M5.5 earthquake was one of the most important events in a chain of the latest seismo-volcanic activity (Okada and Yamamoto, 1991). As a background for discussing those seismo-volcanic activities, we focused on profiling the fine structure of the active region by employing VIBROSEIS** reflection exploration. It is said that VIBROSEIS exploration is less applicable to volcanic or geothermal areas where crustal structures are quite complex (Wright et al., 1985; Ikawa et al., 1987). The VIBROSEIS method, however, is the best way to visualize the structure under volcanic region to the minutest details (Suzuki et al., 1991).

Received September 1, 1990; Accepted February 6, 1991

* To whom correspondence should be addressed.

** Trademark of Continental Oil Company. 


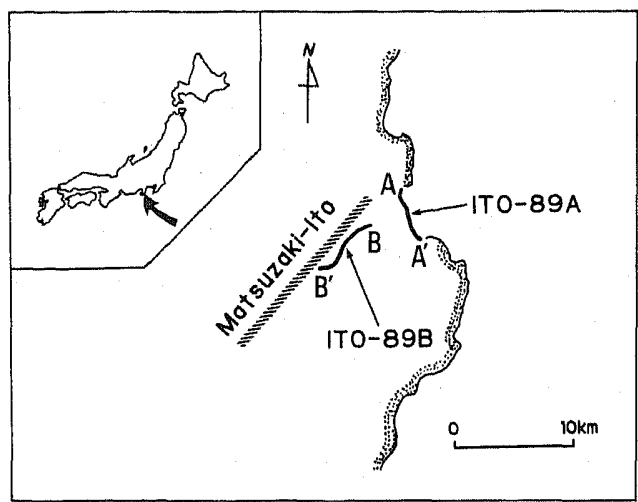

Fig. 1. Two VIBROSEIS reflection exploration lines, ITO-89A $\left(\mathrm{A}-\mathrm{A}^{\prime}\right)$ and ITO-89B (B-B'), and the refraction line Matsuzaki-Ito.

Two exploration lines, ITO-89A and B, shown in Fig. 1, were planned taking the swarm activity and social conditions into consideration. One of the exploration lines, ITO-89A, directly profiles the fault zone of the M5.5 earthquake and the associated swarm region. The other line, ITO-89B, refers to a typical profile for the area of lower seismic activity. This line crosses an extension of the fault strike of the M5.5 earthquake. Along the line from Matsuzaki to Ito (Fig. 1, M-I line), Yoshii et al. (1985) surveyed the crustal structure by seismic refraction. The line ITO-89B is located close to and almost parallel to the M-I line. Both structures from the reflection and refraction exploration are compared and cross checked with each other.

\section{Data Acquisition}

VIBROSEIS reflection exploration along the lines ITO-89A and ITO-89B were carried out in 20 days from the end of August to the middle of September, 1989. The length of the lines is 4.3 and $5.9 \mathrm{~km}$ for the lines $\mathrm{A}$ and $\mathrm{B}$, respectively. Specifications of the measurement are summarized in Table 1. The location of shots and receiving points were determined by leveling and triangulation survey.

Field data of the line ITO-89A were acquired by adopting the diversity stack method (Anderson and McMechan, 1990) in place of the normal vertical stack, because traffic noises were heavy. It is well known that the diversity stack is effective to a burst noise like a traffic noise (Klemperer, 1987). Figure 2 is a comparison of seismic field records; the left was acquired by the normal vertical stack and the right was processed by the diversity stack method. It is seen that the $\mathrm{S} / \mathrm{N}$ ratio is somewhat improved by the diversity stack. In contrast, it needed no special effort for data acquisition along the line ITO-89B. An example of the field record along line B is shown in Fig. 3.

All of the field records were processed in accordance with standard procedures, such as waveform reformation, common depth point (CDP) gathering, velocity analysis, normal moveout (NMO) correction, and CDP stacking. We produced profiling sections 
Table 1. Specifications of measurements.

\begin{tabular}{ll}
\hline Source & \\
Vibrator & 13.5 ton three mobiles \\
Shot interval & $30 \mathrm{~m}$ \\
Sweep frequency & $8-44 \mathrm{~Hz}$ \\
Sweep length & 16 or $24 \mathrm{~s}$ \\
Sweep mode & linear up sweep \\
Sweep number/shot & 15 or 10 \\
Shot pattern & $2 \mathrm{~m}$ mesh linear array/shot \\
\hline Observation & \\
Receiver interval & $10 \mathrm{~m}$ \\
Geophone frequency & $10 \mathrm{~Hz}$ \\
Geophone number/receiver & 12 \\
Receiver pattern & $0.9 \mathrm{~m} \mathrm{mesh} \mathrm{linear} \mathrm{array/receiver}$ \\
\hline Recorder & \\
Data aquisition system & DFS-V \\
Channel number & $96 \mathrm{channels}$ \\
Sampling interval & $4 \mathrm{~ms}$ \\
Record length & 21 or $29 \mathrm{~s}$ \\
Filter & $8-64 \mathrm{~Hz}$ \\
CDP multiplicity & 16 folds \\
\hline
\end{tabular}

through a depth conversion step. The modified time-term method was used for static corrections prior to the CDP stacking process. The migration process used prior to or after CDP stacking was not effective because high velocity reflectors appeared at shallower depths.

\section{Results}

Field records along the lines ITO-89A and B (see Figs. 2 and 3) show relatively a good $\mathrm{S} / \mathrm{N}$ ratio for the two-way time range within $2 \mathrm{~s}$, therefore the crustal structures estimated for this range are focused upon in the present study. For the line ITO-89B, the basic structure of the Izu Peninsula will be discussed through comparisons with the refraction result of Yoshii ct al. (1985). For the line ITO-89A, we will consider the crustal structure of the seismic swarm area in relation to the seismo-volcanic activity.

\subsection{Profile along the line ITO-89B}

Figure 4 shows the processed seismic section along the line ITO- $89 \mathrm{~B}$. The crustal structure within $2 \mathrm{~s}$ seems to be made up of three layers. The uppermost layer B1 has the bottom of intense reflections from shallower depths within $0.5 \mathrm{~s}$. Those reflectors are seen to be broken here and there. We suppose that discontinuities of the reflector may be faults or geological boundaries. The layer under this intense reflection group seems to be rather transparent. The layer B2 is characterized by such a transparency. Finally, another weaker reflection group from the deeper part is recognized at around $1.0 \mathrm{~s}$. The layer covered by those reflectors is B3 which builds up the basement of the

Vol. 39, No. 1, 1991 


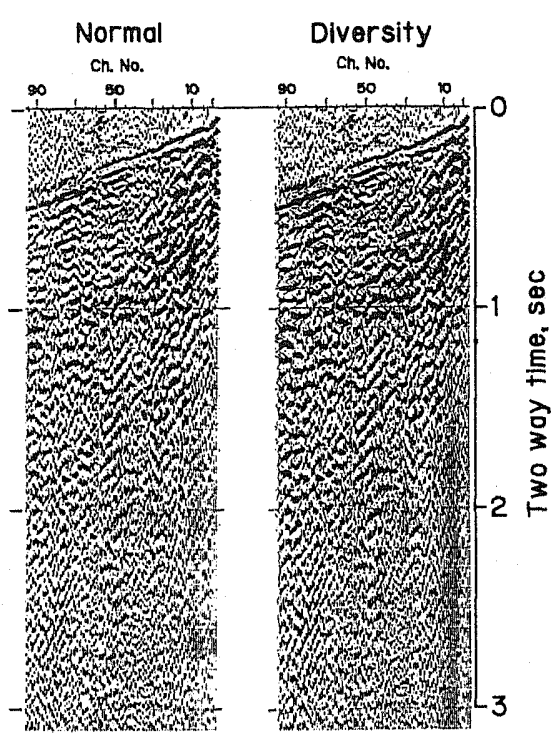

Fig. 2

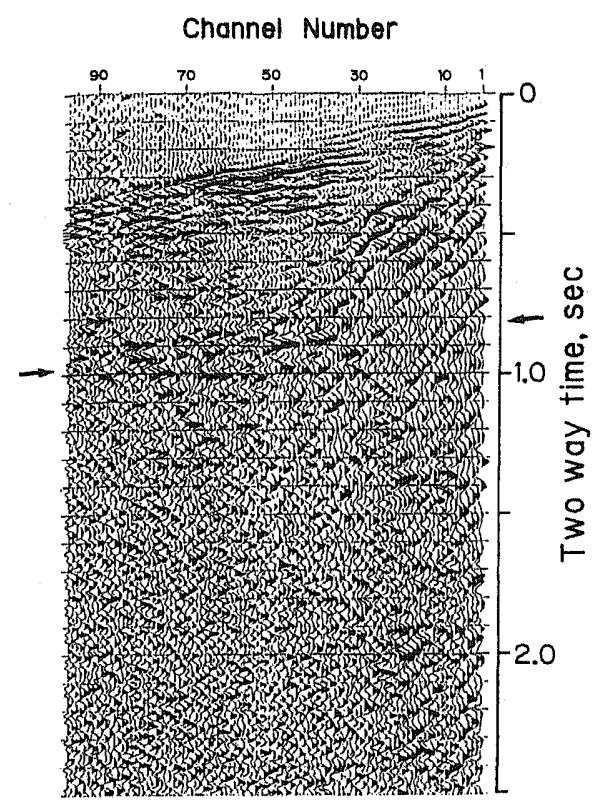

Fig. 3

Fig. 2. Comparison of effects between the normal and the diversity stack method applied for field record along the line ITO-89A.

Fig. 3. Example of the field record along the line ITO-89B. A pair of arrows indicates a weak but a certain reflection phase.

Izu Peninsula. The layer B3 becomes again rather reflective than above.

Figures 5 and 6 show examples of the velocity analysis section for the lines ITO-89A and $\mathrm{B}$, respectively, together with the NMO velocity function which was used for stacking in the specified CDP. These sections are the contourized version of the constant velocity stacking analysis. On those velocity analysis sections, we can identify some reflections around $1 \mathrm{~s}$ with reasonable stacking velocities in spite of the fact that the amplitude and continuity of those reflections are poor. Deeper reflections with poor continuity are occasionally identified on the velocity analysis section observed in the volcanic areas. The interval velocity of the layers B1 and B2 was roughly estimated as 2.6 and $3.5-4.0 \mathrm{~km} / \mathrm{s}$, respectively, referring to the results of the velocity analysis. Since the velocity of the layer B3 is not resolved by the velocity analysis, we assumed $5.0 \mathrm{~km} / \mathrm{s}$ referring to Yoshii et al. (1985).

In Fig. 7, the present result is compared with those from Yoshii et al. (1985) in terms of the time-term. It is reasonable that the time-term obtained from the refraction exploration is nearly equal to one half of the two-way time from the reflection. The two-way times plotted on Fig. 7 were determined by using field monitor records such as in Fig. 3. In Fig. 3, a weak but certain reflection phase, indicated by arrow, is recognized, and easily picked up. It is also shown in Fig. 7 that the crustal structure 


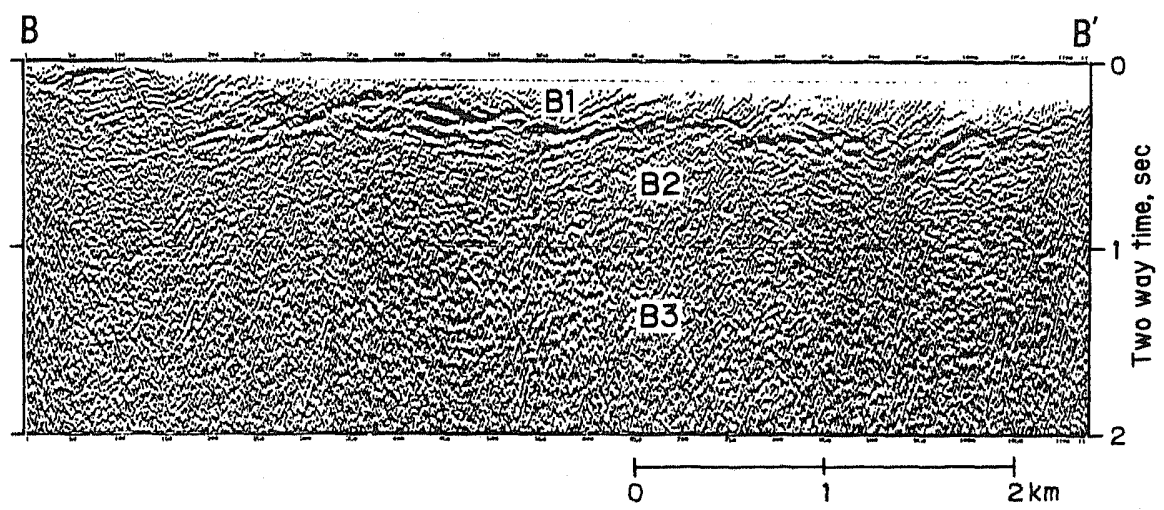

Fig. 4. Two-way time profile along the line ITO-89B.

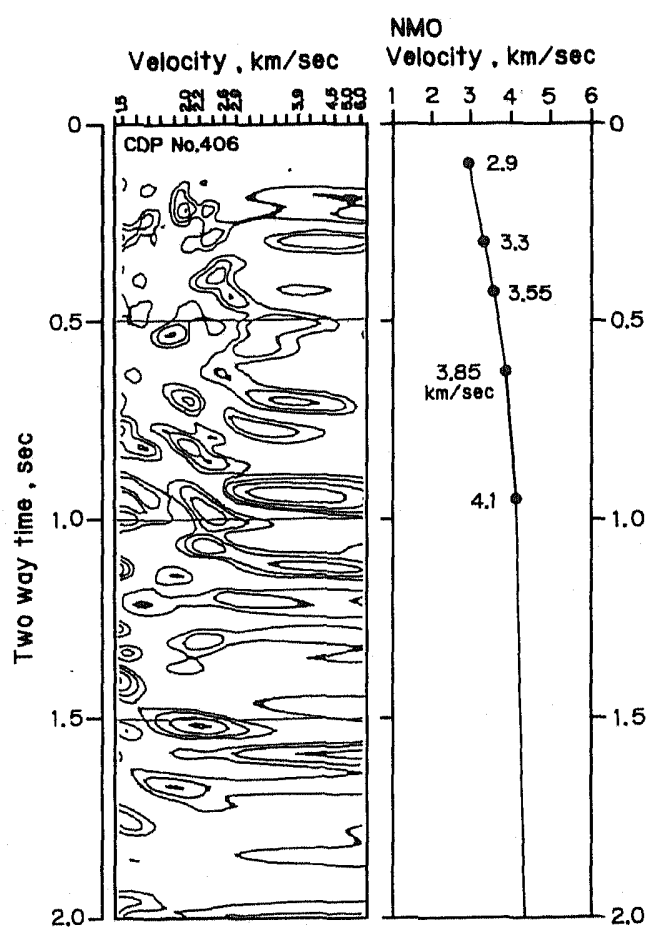

Fig. 5

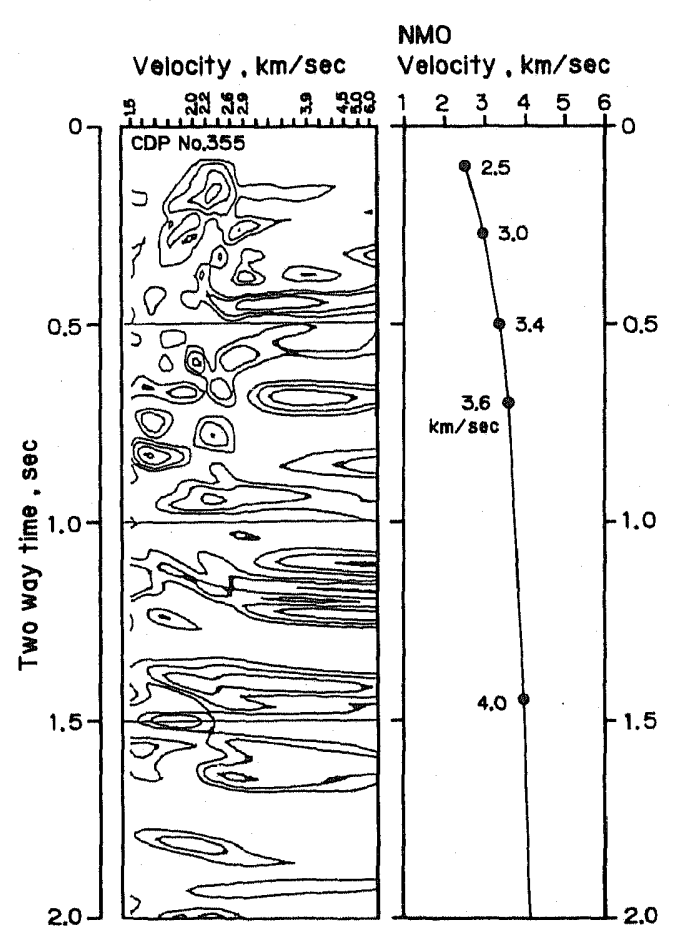

Fig. 6

Fig. 5. Contour map of the constant velocity stacking analysis for the line ITO-89A.

Fig. 6. Contour map of the constant velocity stacking analysis for the line ITO-89B. 

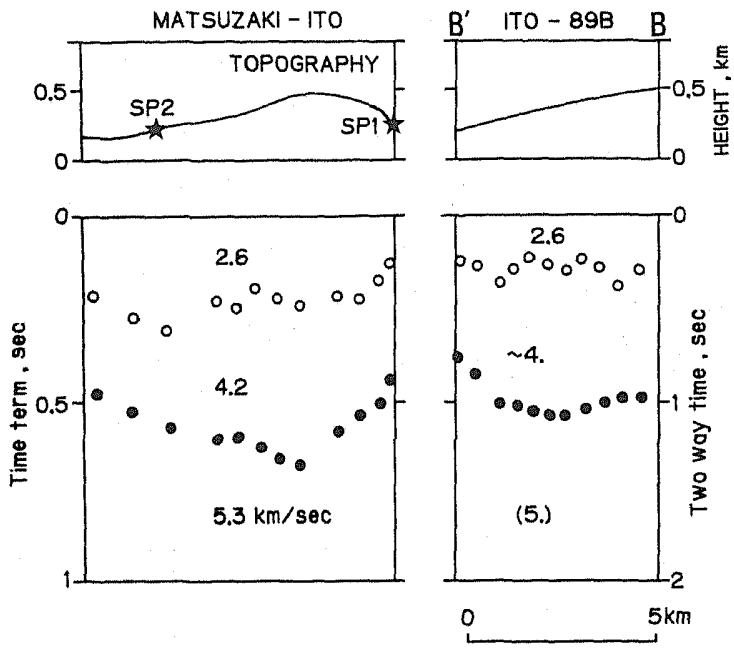

Fig. 7. Comparison of time-term obtained from the refraction exploration along the line Matsuzaki-Ito (after Yoshii et al., 1985) with two-way times from the reflection along the line ITO-89B.

along the M-I refraction line is made up of three layers, and the velocity of each layer is $2.6,4.2$, and $5.3 \mathrm{~km} / \mathrm{s}$ from top to bottom, respectively (Fig. 7, left). Those velocity values and the layer constitution correspond with the reflection profile of the present study (Fig. 7, right). But total time-terms from the refraction survey are generally larger than those from the reflection. Time-term contributions of the middle layer do not differ between both results. This may result from a difference in thickness of the uppermost layer. The fact that the refraction line runs through one of the low Bouguer anomaly areas supports the above interpretation in terms of the thickness difference of surface layer.

\subsection{Profile along the line ITO-89A}

The two-way time profile along the line ITO-89A is shown in Fig. 8. We can easily see in this figure that the crustal structure along this line is made up of three layers: the uppermost layer B1 bounded by the intense reflections within $0.5 \mathrm{~s}$, the transparent layer B2, and the basement B3 under the rather weak reflectors around $1.0 \mathrm{~s}$. Existence of this weak reflection is also supported by the velocity analysis section shown in Figs. 5 and 6. Those features are essentially the same in the line ITO-89B (Fig. 4). In detail, layer $\mathrm{B} 1$ is slightly thinner and has a higher velocity of $2.6-2.9 \mathrm{~km} / \mathrm{s}$ than line ITO-89B. In addition to those minute differences, it is the most interesting that the reflection pattern becomes irregular around $\mathrm{A}$ and $\mathrm{C}$ shown in Fig. 8. Hereafter in this section, we will focus on a meaning of those pattern irregularities.

For the location $\mathbf{A}$, the incoherent patterns appear in the shallow part just below the ground surface. The upper part of Fig. 9 shows travel times of the first arrival for all shots along the line ITO-89A, which were picked up on the field records such as Fig. 2. It is clearly seen that an early arrival group is branching off at about $0.2 \mathrm{~km}$ 


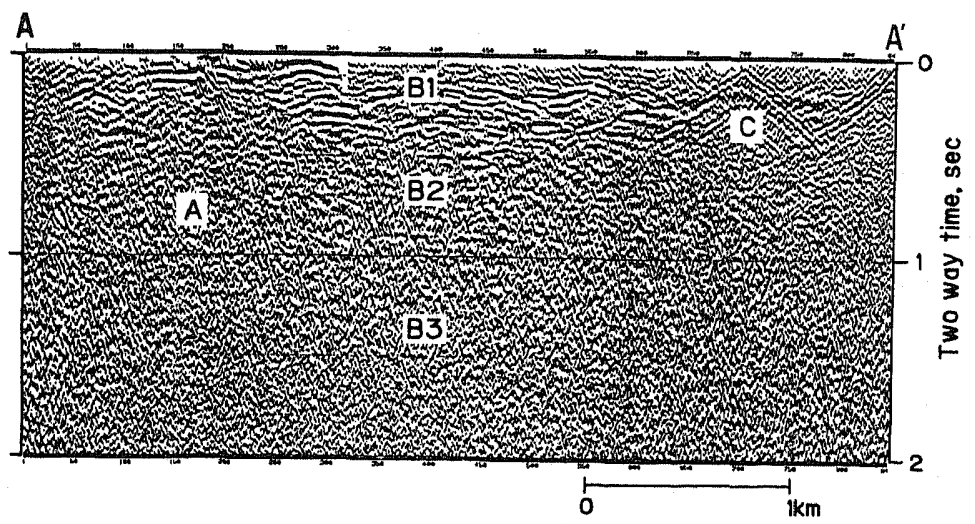

Fig. 8. Two-way time profile along the line ITO-89A.
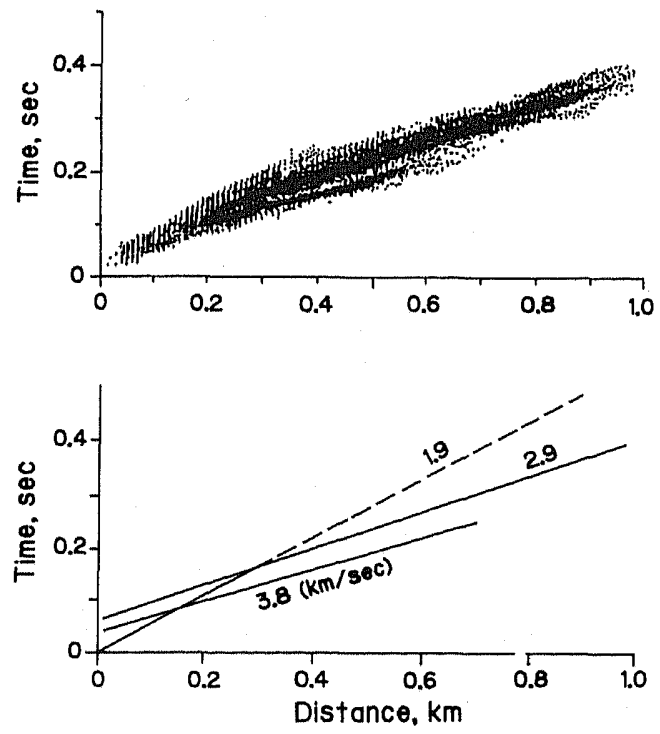

Fig. 9. Upper: plot of first arrivals picked up on field records. Lower: averaged travel time curves for two groups of refraction phases and for direct phases.

through $0.7 \mathrm{~km}$. Almost all dots composing this high velocity branch were observed for shots in the limited range near the location A. Those facts indicate that a high velocity layer rises up to the ground surface. Average travel time curves are shown in the lower part of Fig. 9. The velocity of $3.8 \mathrm{~km} / \mathrm{s}$ is determined for this high velocity body. The near surface structure along the line ITO-89A is roughly estimated on the basis of travel time curves, and is shown in Fig. 10. This figure appears as an intrusive dome-like structure under the location A.

The reflection pattern near location $\mathrm{C}$ is spreading out in a fan-shape, which was not removed by data processing techniques related to the reflection exploration. 


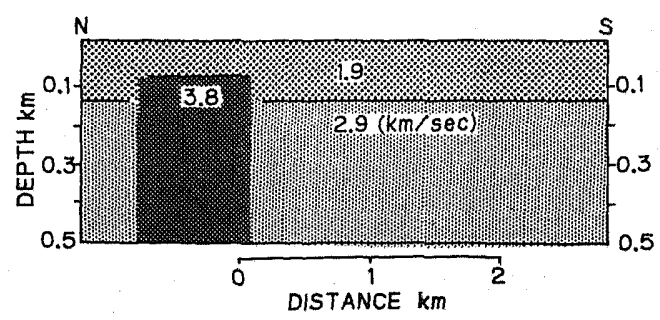

Fig. 10. Rough estimation of the near surface structure along the line ITO-89A on the basis of the travel time curves in Fig. 9.
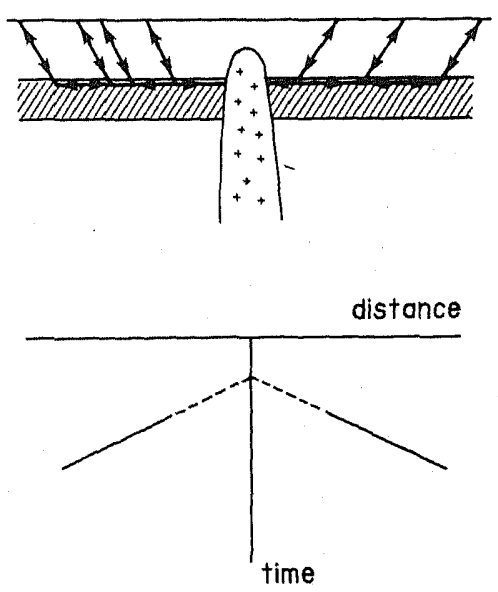

Fig. 11

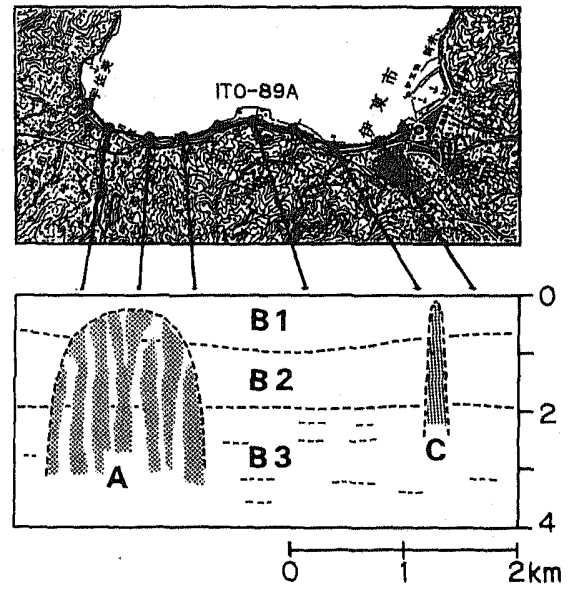

Fig. 12

Fig. 11. Schematic representation of the reflected-refraction phase.

Fig. 12. Interpretation of the reflection profile along the line ITO-89A. Note the vertical axis is depth in place of the two-way time.

Generally, such fan-shaped patterns may be created from the reflected-refraction phase which is schematically shown in Fig. 11 . This phase is basically a refracted wave which is reflected by a vertical boundary or discontinuity (Sheriff and Geldart, 1982). The fan-shaped pattern, therefore, suggests an existence of a near vertical reflector such as fault, dike, salt dome, magma intrusion, and so on. Furthermore, the analysis of first arrivals also suggests that the reflector has a higher velocity than the surrounding medium, but the size of reflector is much smaller than above the dome-like body. Here, we suggest that the dome-like structure near location A may be built up from those smaller-size reflectors.

Figure 12 is a final interpretation of the reflection profile along the line ITO-89A. Considering a relation to geological conditions, layer $\mathrm{B} 1$ is composed of later volcanic extrusions, B2 may correspond to the Miocene formation (Yugashima), and B3 seems to be spread over a wide area that forms the basement of Izu Peninsula. At locations A 
and $\mathrm{C}$, high velocity bodies intrude into the layers $\mathrm{B} 1, \mathrm{~B} 2$, and $\mathrm{B} 3$, which we interprete as aged magma intrusions.

\section{Discussion}

The shallow crust under the Izu Peninsula was shown to be built up of three layers by VIBROSEIS reflection explorations along two lines, ITO-89A and B. The profile along line ITO-89A exhibits an interesting figure of the aged magma intrusions. On the basis of those reflection profiles, we consider a relation to seismo-volcanic activity.

Figure 13 shows a seismicity map observed by National Research Institute for Earth Science and Disaster Prevention (NIED). The fault trace of M5.5 earthquake is shown together with the fault plane solution. According to Fukuyama et al. (1991), the M5.5 earthquake is a doublet, and the second event includes a high stress drop rupturing which may be an asperity. The asperity is located at point e shown in Fig. 13, and coincides with the edge of the high velocity intrusion revealed near location $\mathrm{A}$ on line ITO-89A. This suggests the aged magma intrusions may have created the seismic asperity.

Ueki et al. (1990) showed by means of precise observation of microearthquakes that seismic activity near and around Ito was concentrated to the depth range from 2 to $4 \mathrm{~km}$. The upper limit of the earthquake swarm, $2 \mathrm{~km}$, correctly coincides with the

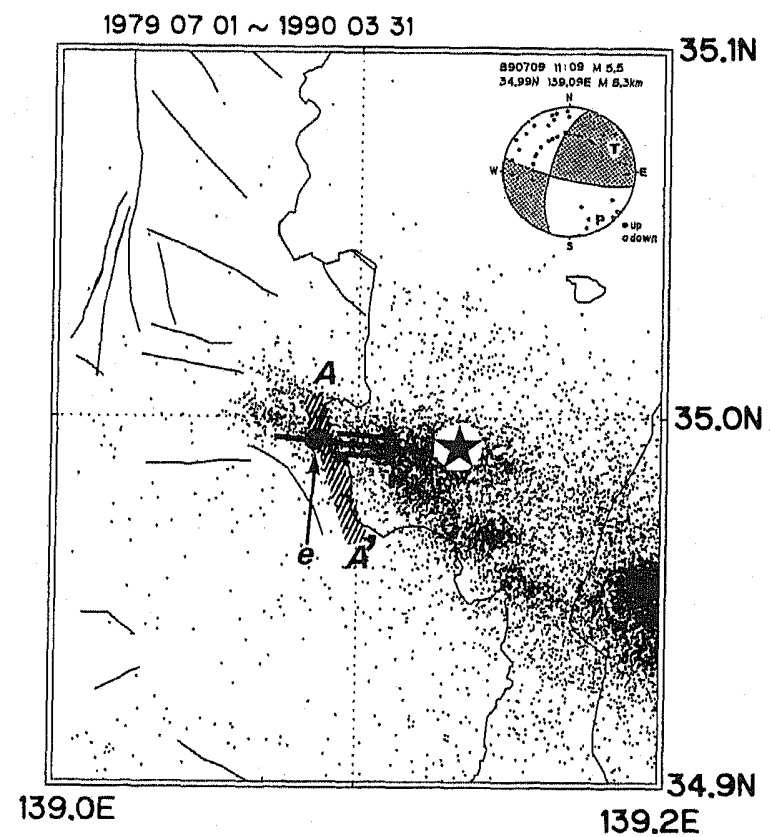

Fig. 13. Seismicity map in and around Ito together with the fault trace, and the mechanism of M5.5 earthquake on July 9, 1989, and the exploration line ITO-89A (A-A'). e shows the location of asperity accompanied with the M5.5 earthquake (after Fukuyama et al., 1991). The star represents the location of submarine volcanic eruption on July 13, 1989. 
depth of the basement B3 (see Fig. 12). Therefore, earthquakes in this area occurred in layer B3, not in layer B1 or B2. It is also interesting that the swarm activity shown in Fig. 13 seems to be limited to the area south of the aged magma intrusion. Those facts suggest that the swarm activity in the region near Ito is closely related to the irregular structure of the shallow crust as in the magma intrusion shown in Fig. 12. We can expect that seismic reflection exploration may help to visualize underground structure from future earthquakes.

The authors wish to express their sincere thanks to Drs. H. Suzuki and Y. Okada of NIED for their discussions and suggestions about the tectonics around the Izu Peninsula. This research was funded by the special coordination funds for promoting science and technology managed by the Science and Technology Agency of Japan.

\section{REFERENCES}

Anderson, R. G. and G. A. McMechan, Weighted stacking of seismic data using amplitudedecay rates and noise amplitudes, Geophys. Prospect., 38, 365-380, 1990.

Fukuyama, E., S. Kinoshita, and F. Yamamizu, Unusual high-stress drop subevent during the M5.5 earthquake, the largest event of the 1989 Ito-oki swarm activity, Geophys. Res. Lett., 1991 (in press).

Ikawa, T., O. Nakagome, and K. Okazaki, Reflection seismic exploration in geothermal areasPresent technology and future-, J. Jpn. Geotherm. A., 24, 60-72, 1987 (in Japanese).

Klemperer, S. L., Seismic noise-reduction techniques for use with vertical stacking: an empirical comparison, Geophysics, 52, 322-334, 1987.

Okada, Y. and E. Yamamoto, A model for the 1989 seismo-volcanic activity off Ito, central Japan, derived from crustal movement data, J. Phys. Earth, 39, 177-195, 1991.

Sheriff, R. E. and L. R. Geldart, Exploration Seismology, Vol. 1, Cambridge University Press, Cambridge, 1982.

Suzuki, H., K. Kasahara, M. Ohtake, A. Takahashi, T. Ikawa, S. Abe, and Y. Kawabe, Magmatic activity of Izu-Oshima Volcano, Japan, as inferred from a seismic reflection survey, $J$. Volcanol. Geotherm. Res., 1991 (in press).

Ueki, S., Y. Morita, T. Nishimura, S. Horiuchi, and H. Hamaguchi, The seismicity accompanying the eruption of a submarine volcano off Izu Peninsula, Japan, EOS. Trans. Am. Geophys. Union, 71, 960, 1990.

Wright, P. M., S. H. Ward, H. P. Ross, and R. C. West, State-of-the-art geophysical exploration for geothermal resources, Geophysics, 50, 2666-2699, 1985.

Yoshii, T., S. Asano, S. Kubota, Y. Sasaki, H. Okada, T. Masuda, T. Moriya, and H. Murakami, Crustal structure in Izu Peninsula, central Japan, as derived from explosion seismic observations 2. Ito-Matsuzaki profile, J. Phys. Earth, 33, 435-451, 1985. 